\title{
Testing of newly developed functional surfaces under pure sliding conditions
}

\author{
Godi, Alessandro; Mohaghegh, Kamran; Grønbæk, J.; Klit, Peder; De Chiffre, Leonardo
}

Published in:

Tribology Letters

Link to article, DOI:

$10.1007 / \mathrm{s} 11249-013-0162-6$

Publication date:

2013

Link back to DTU Orbit

Citation (APA):

Godi, A., Mohaghegh, K., Grønbæk, J., Klit, P., \& De Chiffre, L. (2013). Testing of newly developed functional surfaces under pure sliding conditions. Tribology Letters, 51(1), 171-180. https://doi.org/10.1007/s11249-013$0162-6$

\section{General rights}

Copyright and moral rights for the publications made accessible in the public portal are retained by the authors and/or other copyright owners and it is a condition of accessing publications that users recognise and abide by the legal requirements associated with these rights.

- Users may download and print one copy of any publication from the public portal for the purpose of private study or research.

- You may not further distribute the material or use it for any profit-making activity or commercial gain

- You may freely distribute the URL identifying the publication in the public portal

If you believe that this document breaches copyright please contact us providing details, and we will remove access to the work immediately and investigate your claim 


\title{
Testing of newly developed functional surfaces under pure sliding conditions
}

\author{
A. Godi ${ }^{1}$, K. Mohaghegh ${ }^{1}$, J. Grønbæk ${ }^{2}$, P. Klit ${ }^{1}$, L. De Chiffre ${ }^{1}$ \\ ${ }^{1}$ Department of Mechanical Engineering, Technical University of Denmark (DTU), \\ Produktionstorvet 425, 2800 Kgs. Lyngby, Denmark. \\ ${ }^{2}$ STRECON A/S, Stødagervej 5, 6400 Sønderborg, Denmark. \\ Corresponding author: Alessandro Godi (alego@mek.dtu.dk).
}

\begin{abstract}
The employment of surface texturing for improved tribological contacts has spread over the years. The possibilities of designing and manufacturing textured surfaces with predetermined geometries have multiplied as well as the need of performing experimental laboratory tests before applying the surfaces in an industrial context. In this paper a number of experimental tests were performed using a novel test rig, called Axial Sliding Test, simulating the contact of surfaces under pure sliding conditions. The aim of the experiments is to evaluate the frictional behavior of a new typology of textured surfaces, the so-called multifunctional surfaces characterized by a plateau area able to bear loads and a deterministic pattern of lubricant pockets. Six surface typologies, namely three multifunctional and three machined using classical processes were chosen to slide against a mirror-polished counterpart. A number of experiments were carried out at different normal pressures employing for all specimens the same reciprocating movement and the same lubrication. The measured friction forces were plotted against the incremental normal pressure and the friction coefficients were calculated. The results comparison showed clearly how employing multifunctional surfaces can reduce friction forces up to $50 \%$ at high normal loads compared to regularly ground or turned surfaces. Friction coefficients approximately equal to 0.12 were found for classically machined surfaces, whereas the values were 0.06 for multifunctional ones. All the specimens were characterized before and after testing. Wear occurrence was not detected on the tested surfaces except on the mirror-polished one which underwent all the experiments.
\end{abstract}

Keywords: functional surfaces, sliding, friction, experimental tests. 


\section{Introduction}

Surface texture has been widely acknowledged playing a decisive role in the functional behavior of engineering parts $[1,2]$. In recent years, the progress in process technologies and control has allowed the design of surfaces containing features or having particular geometries in order to provide a specific functional performance [3]. When a textured surface is designed to provide tribological properties, the objective is to reduce friction losses and wear occurrence, issues whose importance has been growing over the years $[1,4]$. Numerous different techniques can be employed for surface texturing, classified in adding, removing and moving material techniques [1]. Probably the most notorious one is plateau-honing, widely used in the automotive industry in the last three decades. Plateau-honing consists in a two-steps process in which a coarser premachining operation is followed by a finishing process removing the peaks that would be typically worn out during the run-in period. The resulting surface has a plateau area capable of carrying loads and deeper, crossed valleys able to store and provide extra lubrication [5-8]. Numerous shapes, sizes and distributions of the lubricant reservoirs have been under the attention of researchers all over the world [9-17]. Grooves, dimples, herringbone patterns and crossed texture have all shown promising results in terms of reduction of the friction coefficient both in machine element and metal forming applications [9, 13-17].

Recently, a novel typology of textured surfaces has been introduced: the so-called multifunctional surfaces (MUFU) [18, 19]. Similarly to plateau-honed surfaces, multifunctional surfaces are produced through a two-step process generating a surface with bearing capabilities and the ability of providing extra-lubrication. Yet, differently from plateau-honing, the pre-machining is a hardturning operation, which provides a deterministic distribution of surface peaks and valleys rather than a stochastic one. The finishing process is a Robot Assisted Polishing (RAP) operation performed on a machine developed by the Danish company Strecon A/S [19]. The RAP machine gradually removes the peaks of the original turned surface yielding a surface with a certain degree of bearing area and a deterministic distribution of lubricant channels (Fig. 1). Thanks to the high control of the RAP machine, a broad variety of MUFU surfaces can be created [18].

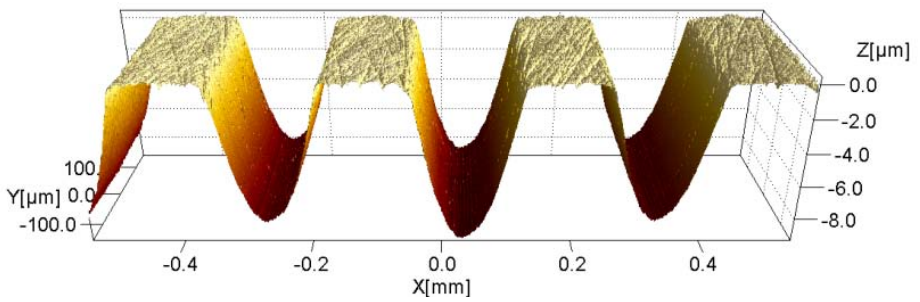

Fig.1. MUFU surface.

In this paper an experimental campaign testing the efficacy of MUFU surfaces under pure sliding conditions for machine elements applications is presented. A newly developed Axial Sliding Test (AST) rig is used for the experiments. Three MUFU surfaces and three conventional machined surfaces are tested in sliding conditions against a mirror-polished surface measuring friction forces. Eventually the friction coefficients are calculated and compared.

\section{Axial Sliding Test rig and settings}

The AST is a novel testing typology lately presented in [20] consisting of four major components: a stripwound Strecon ${ }^{\circledR}$ container, a conical housing, a rod and a sleeve (Fig. 2). During the experiments the only parts in relative motion with respect to each other are the rod and the sleeve, to which the tested surfaces are applied. The rod is made of a chromium-molybdenum-vanadium alloyed steel (Vanadis 6) with a hardness of $62 \mathrm{HRC}$, diameter $Ø 38 \mathrm{~mm}$ and length equal to 135 $\mathrm{mm}$. The sleeve is a $60 \mathrm{~mm}$ long hollow cylinder made of the same material, but slightly harder (64 HRC). Its inner diameter is nominally the same as the rod outer diameter, while the outer diameter is $\varnothing 58 \mathrm{~mm}$. The sleeve is placed inside the housing, which is cylindrical on the inside and with $1^{\circ}$ conicity on the outside (Fig. 2, right). The Strecon ${ }^{\circledR}$ container, which is also $1^{\circ}$ conical on the inside, envelops the conical housing (Fig. 2, left) self-locking on it. Once loaded, the container can maintain a uniform normal pressure on the housing-sleeve system. The stripwinding 
process [21-23] employed to produce the container, gives the ability to distribute the equivalent stress over hundreds of layers, thus avoiding stress concentrations, plastic deformations and pressure losses [23].

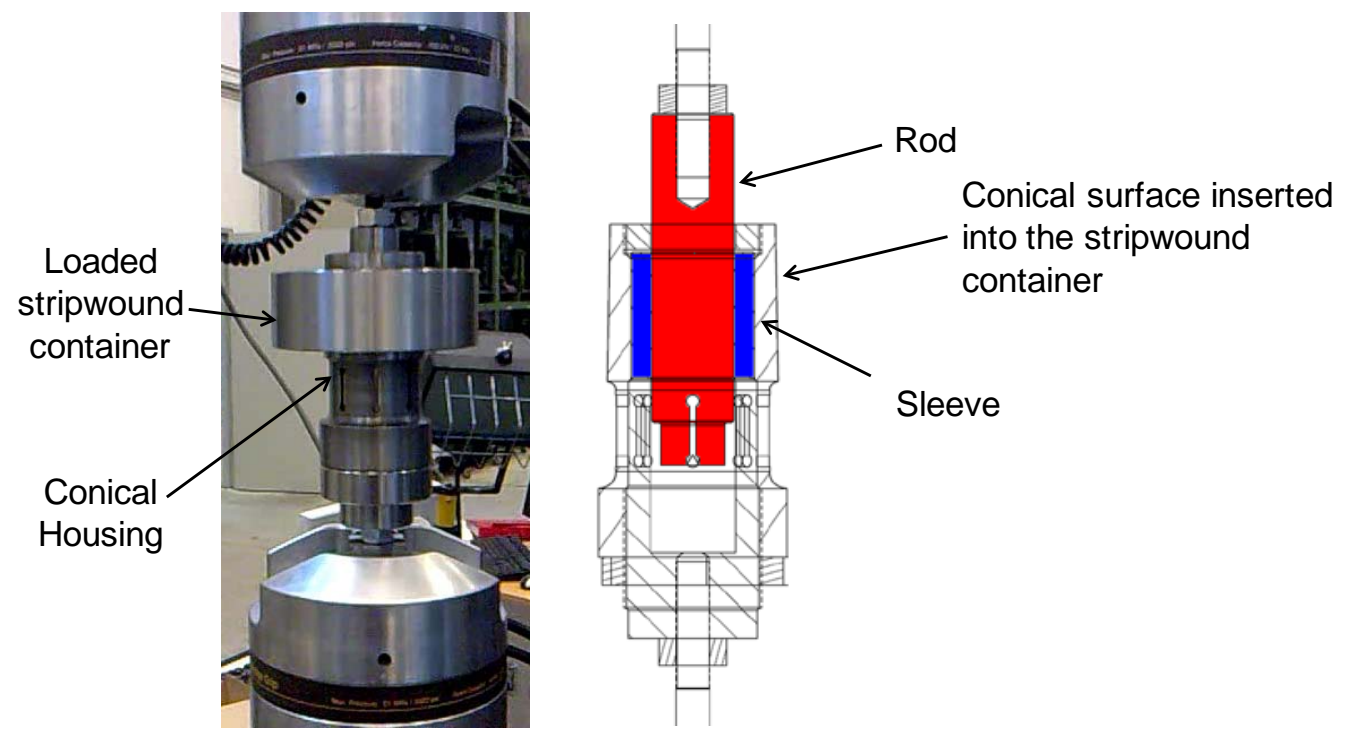

Fig.2. AST mounted on a tensile machine (left) and axial section of the assembled AST (right).

The test consists of two successive operations: loading and reciprocate sliding. The loading operation is performed by pressing the stripwound container down the housing by means of a hydraulic press. It is possible to control the advancement of the container by using a series of calibrated rings [20]. It is unfortunately not possible to know the absolute normal pressure acting on the housing-sleeve system once the pressing operation is done. Therefore, pressing experiments were carried out in order to calibrate and verify a mathematical model based on the theory of multiple shrink fitted rings [24] correlating the container advancement to the increase of normal pressure as explained in [20]. The experiments demonstrated that the normal pressure applied by the housing-sleeve system increases $34 \mathrm{MPa}$ every mm of container advancement when a rod is inserted. After loading, the apparatus is mounted in a fatigue test machine to perform the sliding operation (Fig. 2, left). A movement following a trapezoidal position curve was specified. After a $8 \mathrm{~mm}$ run-in, the movement started with a ramp of $30 \mathrm{~mm}$ run at $1 \mathrm{~mm} / \mathrm{s}$, followed by an idle period (initially $10 \mathrm{~s}$, then reduced to $2 \mathrm{~s}$ ), then a return ramp of $30 \mathrm{~mm}$ at $1 \mathrm{~mm} / \mathrm{s}$ and eventually another idle period. The speed was chosen deliberately low so that no hydrodynamic effect occurs during the test and the most severe tribological conditions are achieved. The cycle was repeated ten times with a run-out of $8 \mathrm{~mm}$ after the last cycle. Friction forces were measured throughout the test by a calibrated load cell embedded into the machine at a frequency of 5 points/s. The same lubricant was used for all the specimens, a multipurpose Texaco Multifak ${ }^{\circledR}$ EP2 with a base oil viscosity of $173 \mathrm{cSt}$ at $40^{\circ} \mathrm{C}$ [25].

\section{Specimens selection and characterization}

In order to decrease the degrees of freedom of the test, it was decided that only the rods would have texture applied. Therefore, only one typology of sleeve was employed, mirror-polished to a roughness $\mathrm{Ra}<0.02 \mu \mathrm{m}$ and thus nominally flat compared to the rods (Fig. 3 ). On the other hand, six rods were realized, three using classical manufacturing methods and three multifunctional (Fig. 4). In particular, the regularly machined rods were respectively one fine-turned with feed rate 0.1 $\mathrm{mm} / \mathrm{rev}$, one ground and one polished. The three multifunctional rods were hard-turned with a feed rate $0.3 \mathrm{~mm} / \mathrm{rev}$ but polished at a different level of plateau bearing area. The rods are labeled respectively MUFU20\%, MUFU40\% and MUFU55\%, where the percentage represents the bearing area of the plateaus. All rods which underwent a turning operation were turned with a tool nose radius of $0.4 \mathrm{~mm}$. 

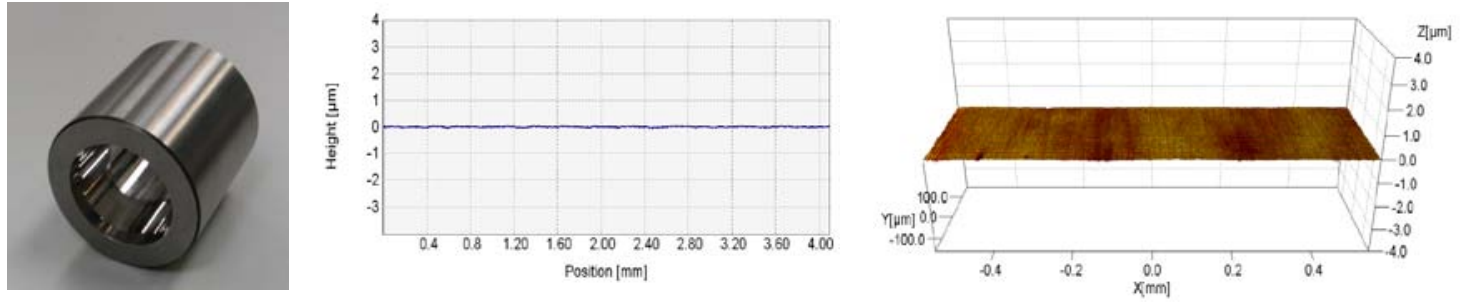

Fig.3. Mirror-polished sleeve used for the experiments (profile and 3D topography).
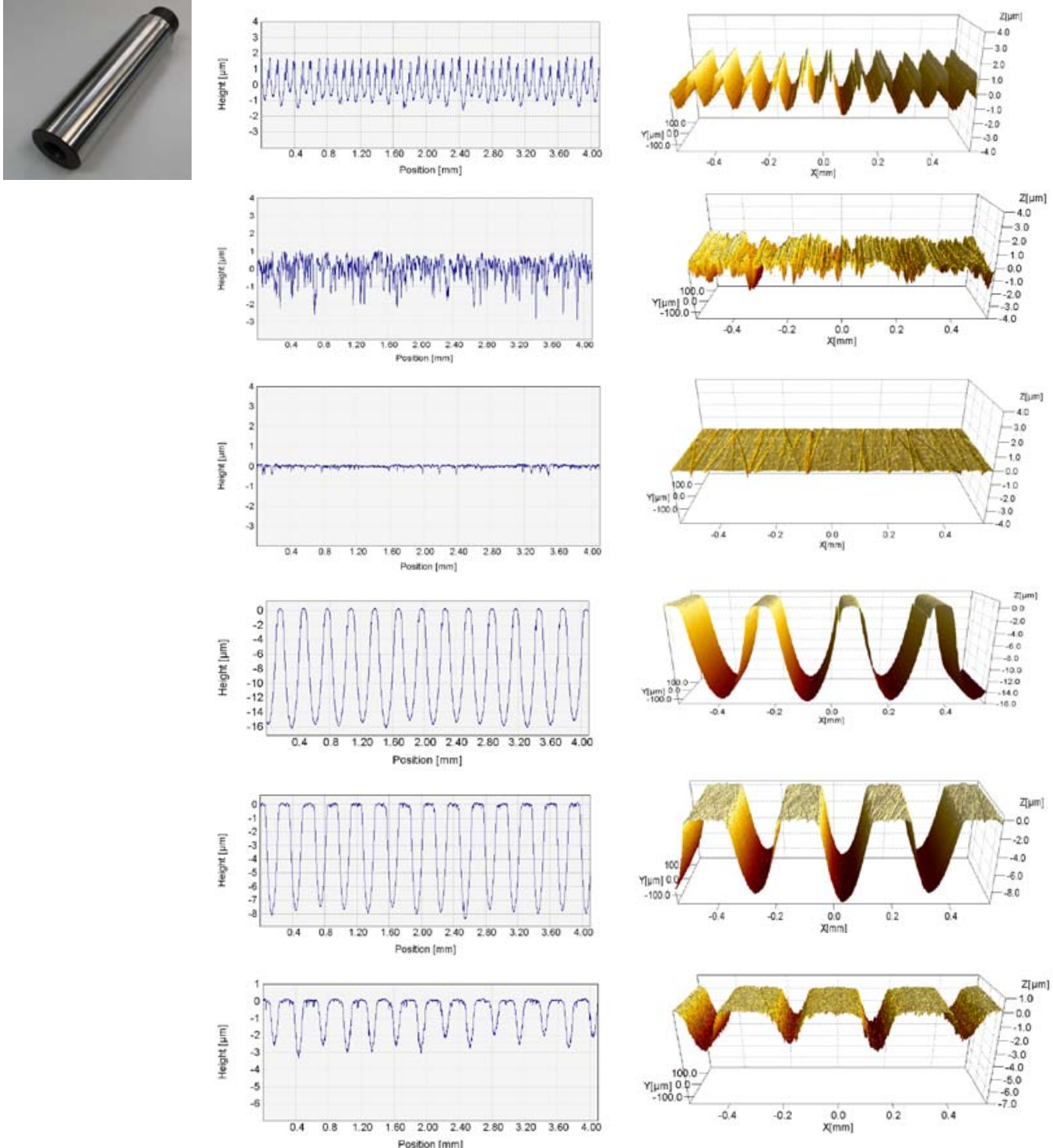

Fig.4. Characterization of selected rods. From the top downwards: fine-turned, ground, polished, MUFU20\%, MUFU40\% and MUFU55\%.

All the specimens were characterized using a calibrated independent datum inductive profilometer (Form Talysurf with 50mm maximum traversing length). The stylus has a diamond probe with a standardized tip radius of $2 \mu \mathrm{m}$. The resolution of the instrument in the vertical direction is $3.2 \mathrm{~nm}$, making it suitable for measurements of fine surfaces without digitalization errors and loss of information. For each specimen 12 profiles were taken in four different positions before and after testing. Each profile has an evaluation length of $4 \mathrm{~mm}$ and was filtered in order to remove form and waviness components. The "traditionally" machined surfaces were filtered with a Gaussian Regression filter of the second order using a cut-off length of $0.8 \mathrm{~mm}$. The filter choice eliminates 
the end-effects of the normal Gaussian Filter and the need of a preliminary removal of the form $[26,27]$. The Ra and Rt values of the obtained profiles were then calculated. The multifunctional rods, conversely, were filtered using more advanced Robust Gaussian Regression filters [18] with $0.8 \mathrm{~mm}$ cut-off length. Moreover, the characterization procedure employed was also different. Field parameters such as Ra are traditionally used for monitoring the production process, but they do not provide any information about the functionality of a surface [26]. Therefore, when a surface is designed for having functional properties, more specific and advanced characterization methods are required. In the case of MUFU surfaces a new methodology has been recently developed detecting and separating the plateau and valley features [28]. The two features can thus be analyzed separately as they were two different profiles (Fig. 5). The plateaus, outcome of the RAP process, can be characterized by a field parameter, whereas the valleys are analyzed in terms of the amount of lubrication they contain. The ratio between the volume of lubricant contained in one evaluation length and the evaluation length is deemed a reasonable parameter for this scope. "Equivalent film thickness" can be interpreted as the thickness of a lubricant film separating two ideally flat surfaces if all the oil trapped in the valleys was utilized. Eventually, the MUFU rods characterization yielded two parameters: the Ra of the plateaus and the "equivalent film thickness". The Rt of the entire profile is however provided for comparison with the other surfaces. Furthermore, for visualization purposes, a 1x0.3 mm 3D topography was taken for each sample before and after testing with the same instrument.
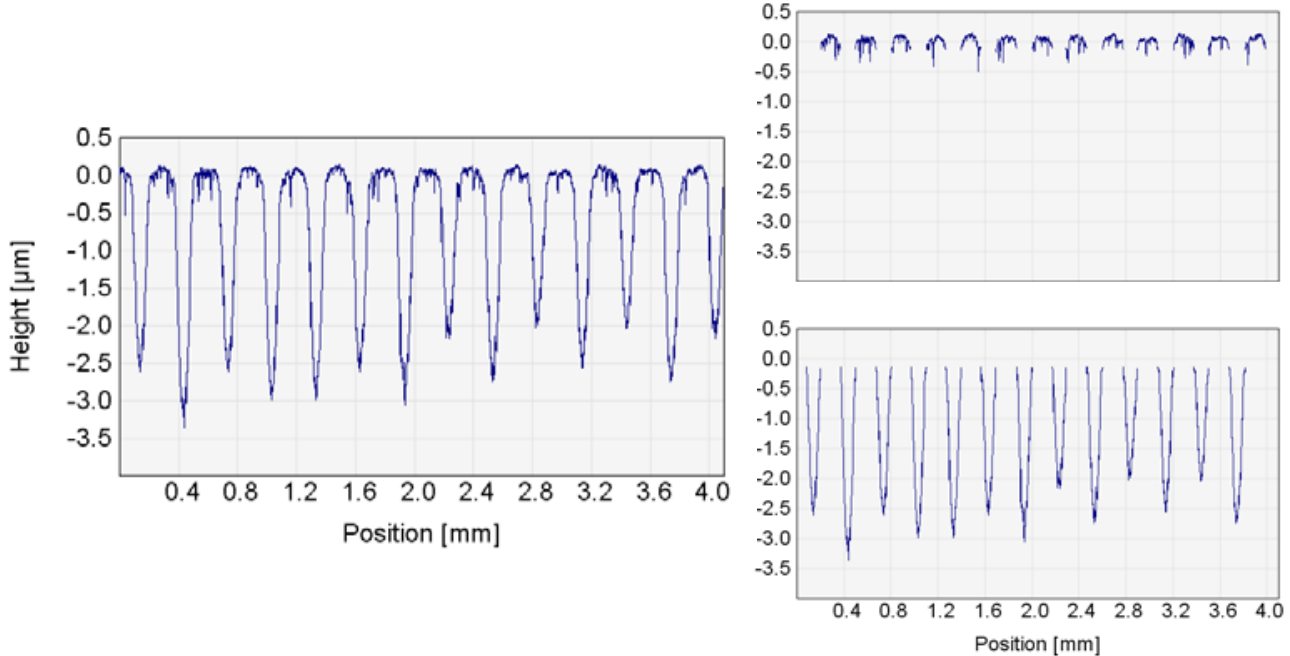

Fig.5. Separation of plateaus and valleys in MUFU profiles characterization.

In Table 1 the roughness results before testing are listed. It is conspicuous that the mirror-polished sleeve is characterized by a roughness of at least 1 order of magnitude lower than all the other surfaces (except the polished rod). The fine-turned and the ground rods have roughnesses of the same order, with the ground one slightly rougher. It is anyhow evident from Fig. 4 the deterministic nature of the turned process in contrast with the stochastic nature of the ground one. The Rt value of the fine-turned rod and the MUFU55\% are similar, with the multifunctional one presenting broader valleys due to the higher feed-rate employed. The three MUFU rods were manufactured with the same tool and same feed-rate, therefore an increasing bearing area of the plateaus corresponds to a lower amount of lubrication stored in the valleys. Finally, the roughness of the plateaus is comparable with the one of the polished rod, especially in the case of the MUFU40\% rod. That was expected since they are produced by using the same RAP process. Looking at the 3D plots of Fig.1 and Fig.4, the similarities are highlighted. The polished rod presents transversal scratches, remainders from the pre-machining process, and crossed scratches from the RAP polishing. The same crossed scratches can be detected in the plateaus of the multifunctional rod. These two surfaces present thus an extremely similar tribological contact with the sleeve. 
Table 1. Characterization of AST rods and sleeve before testing.

\begin{tabular}{|c|c|c|c|c|c|c|c|c|}
\hline $\begin{array}{l}\text { Specimen } \\
\text { Type }\end{array}$ & \multicolumn{2}{|c|}{$\mathrm{Ra}[\mu \mathrm{m}]$} & \multicolumn{2}{|c|}{ Rt [ $\mu \mathrm{m}]$} & \multicolumn{2}{|c|}{$\begin{array}{l}\text { Ra plateaus } \\
{[\mu \mathrm{m}]}\end{array}$} & \multicolumn{2}{|c|}{$\begin{array}{l}\text { Eq. Film } \\
\text { thickness [ } \mu \mathrm{m}]\end{array}$} \\
\hline & Aver. & St. dev. & Aver. & St. dev. & Aver. & St. dev. & Aver. & St. dev. \\
\hline $\begin{array}{l}\text { Mirror-polished } \\
\text { sleeve }\end{array}$ & 0.013 & 0.001 & 0.146 & 0.042 & & & & \\
\hline $\begin{array}{l}\text { Fine Turned } \\
\text { rod }\end{array}$ & 0.752 & 0.005 & 3.615 & 0.201 & & & & \\
\hline Ground rod & 0.512 & 0.020 & 4.526 & 0.368 & & & & \\
\hline Polished rod & 0.047 & 0.003 & 0.848 & 0.099 & & & & \\
\hline $\begin{array}{l}\text { MUFU 20\% } \\
\text { rod }\end{array}$ & & & 16.910 & 0.320 & 0.022 & 0.002 & 7.870 & 0.124 \\
\hline $\begin{array}{l}\text { MUFU 40\% } \\
\text { rod }\end{array}$ & & & 9.234 & 0.275 & 0.055 & 0.003 & 2.948 & 0.146 \\
\hline $\begin{array}{l}\text { MUFU 55\% } \\
\text { rod }\end{array}$ & & & 3.619 & 0.284 & 0.037 & 0.003 & 0.619 & 0.021 \\
\hline
\end{tabular}

\section{Test results and discussion}

The tests were performed as described above. With these settings the friction forces curve against time would ideally have the shape of a square wave, with constant friction forces during the constant speed stroke. In Fig. 6 are plotted the position and the forces of a test run with the fineturned rod.

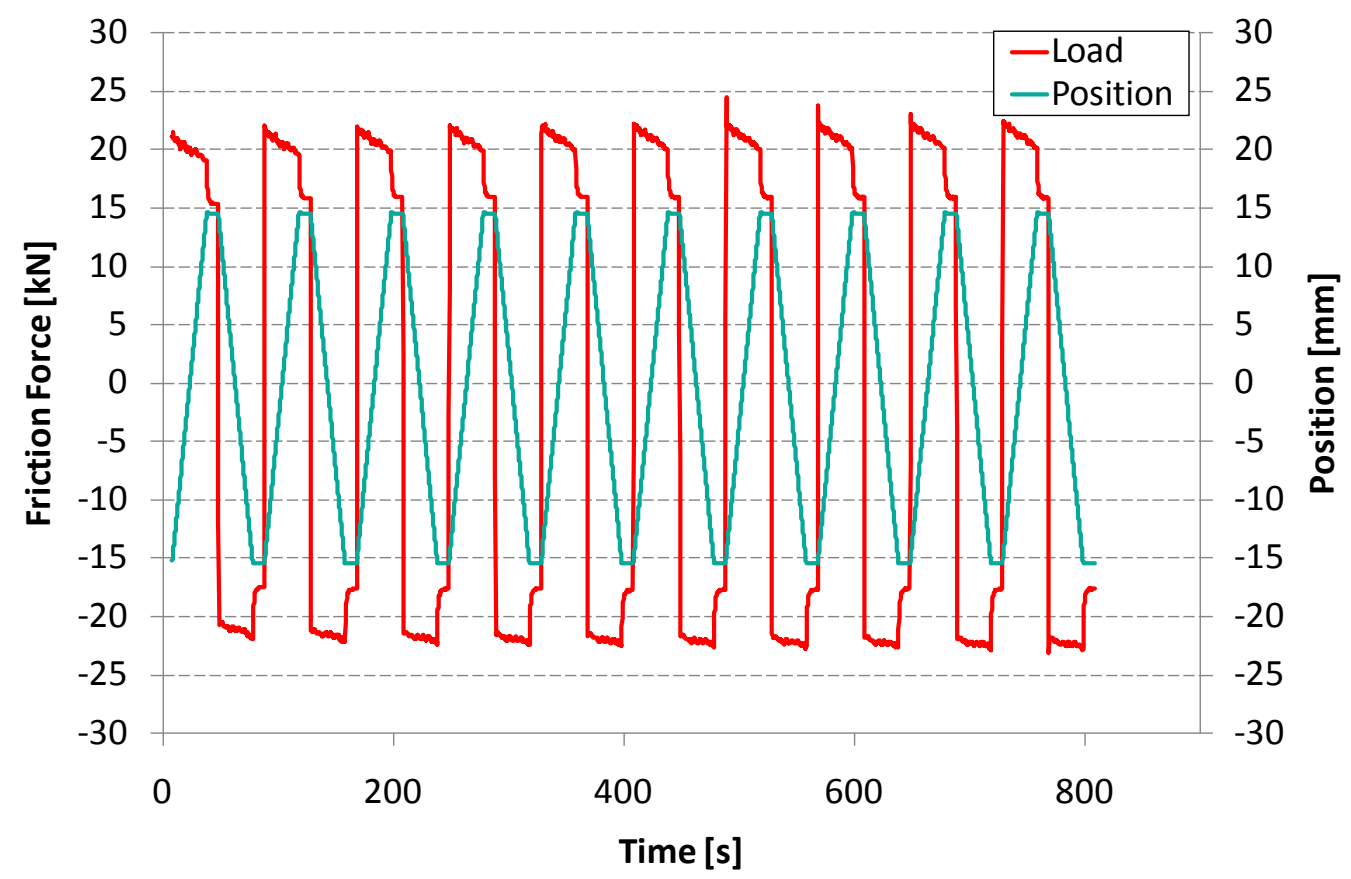

Fig.6. Example of position and friction force measurements while testing the fine-turned rod.

Positive and negative forces differ slightly in absolute value: this may be due to different tribological contact pairs along the two directions. Considering only the positive forces, they are to some extent decreasing during the stroke. The same trend was found when testing the ground and the polished rod. The multifunctional rods exhibited instead different behaviors: MUFU20\% rod had initially constant forces decreasing in the end, MUFU40\% rod showed increasing forces, whereas the MUFU55\% showed a more various trend. A first explanation found in literature could be attributed to hysteretic frictional behaviors that can occur during large-scale motion in pure sliding [29, 30]. This, however, seems not to be the case, since in [29, 30] the pure sliding was performed using an oscillatory, sinusoidal movement where the speed was varying during the stroke. Here, instead, the movement was set to a constant speed $(1 \mathrm{~mm} / \mathrm{s})$, much slower than the 
experiments of [29]. The acceleration/deceleration period was limited to tens of a second (thus tens of $\mathrm{mm}$ ) at the beginning and at the end of the stroke. Hence, if any hysteresis had occurred, it would have had a much smaller effect on the force trends compared to the observed ones. Other explanations for such behaviors must be sought and one can be found by studying the rod geometries, hitherto considered as perfect cylinders. If, instead, the rods present form errors, fewer points will be in contact displaying higher local pressures. The hypothesis is that, with the movement, some points at higher pressure will be drawn out of the loaded zone releasing lightly the rod. Similar geometries will therefore have similar force trends. In order to prove the hypothesis, the form errors must be found and compared to friction force trends. Diameter measurements were then performed every $10 \mathrm{~mm}$ using a CMM (Fig. 7) and the diameter results were plotted in the test zone, i.e. the zone of the rod nominally contacting the sleeve during one ramp.

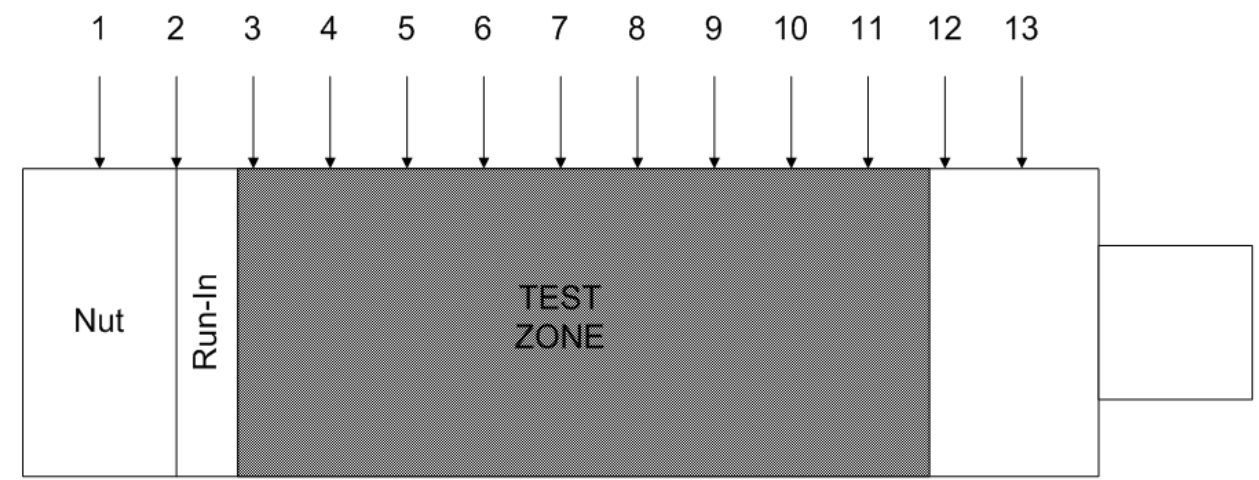

Fig.7. CMM measurement position with the test zone highlighted.

In the left-hand side of Fig. 8 the two most similar rods in terms of geometry are compared: the ground and the polished ones. Although the polished rod has slightly higher diameter than the ground one, their trends are extremely similar, with $5 \mu \mathrm{m}$ difference between the first and the last diameter in both cases. In order to confirm the hypothesis the force trends of the two rods should also be similar. The right-hand side of Fig. 8 displays the friction forces results of the seventh cycle at their respective highest normal load. The friction forces exhibit alike tendencies, slightly descendent (positive forces) as the rod runs, confirming thus the hypothesis.
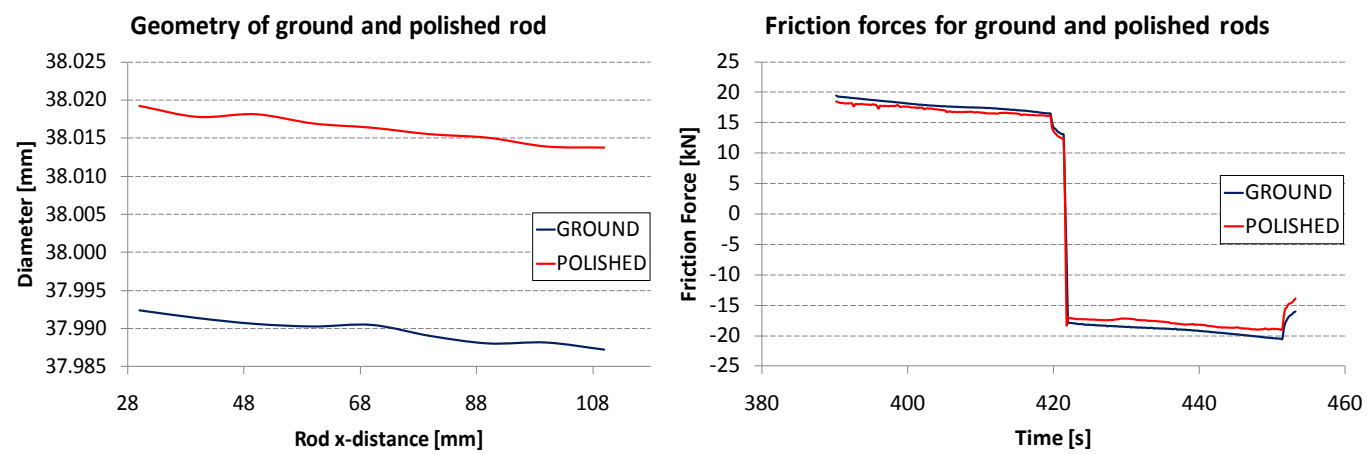

Fig.8. Comparison between the ground and polished rods geometries (left) and friction forces (right).

Acknowledging therefore the presence of form errors affecting the force shape, the analysis of data was performed as follows: for each experiment the last 5 cycles, (the more stable) were considered; the average value of each positive cycle is taken and plotted; the range is utilized as measure of data variation. The reason for using the range rather than the standard deviation is the systematic trends of the force within a period. In Fig. $\mathbf{9}$ the resulting friction stresses are plotted against the normal pressure increase. The friction stresses were calculated by dividing the measured forces by the internal area of the sleeve. The normal pressure increase represents the increment of normal pressure from an artificially chosen "zero-point”. Starting from loose assembly conditions, the stripwound container was made gradually advancing with steps of 0.2 
$\mathrm{mm}$ (i.e. 6.8 MPa of normal pressure increase). The zero-point corresponds to the last assembly conditions leading to friction forces lower than $1 \mathrm{kN}$. From the zero-point the forces were considered relevant (mixed-lubrication regime) and recorded keeping the same advancing step. The ground and the fine-turned rod displayed evidently higher friction stresses compared to the other rods. The polished rod follows initially the MUFU40\% one, but it increases steeply at higher pressures. Generally, the multifunctional rods displayed lower friction forces than the ordinarily manufactured rods. Although the MUFU40\% presented high variations making its assessment governed by high uncertainty, it is safe to conclude that all the MUFU rods caused less friction forces than the turned and the ground rod. Moreover the MUFU55\% and the MUFU20\% rods presented lower friction forces with respect also to the polished rod. As particular instance, it is observed that the friction stresses associated with the MUFU55\% rod at $27.2 \mathrm{MPa}$ of normal pressure increase were half the ones of the fine-turned rod (1.4 MPa against 2.8 MPa).

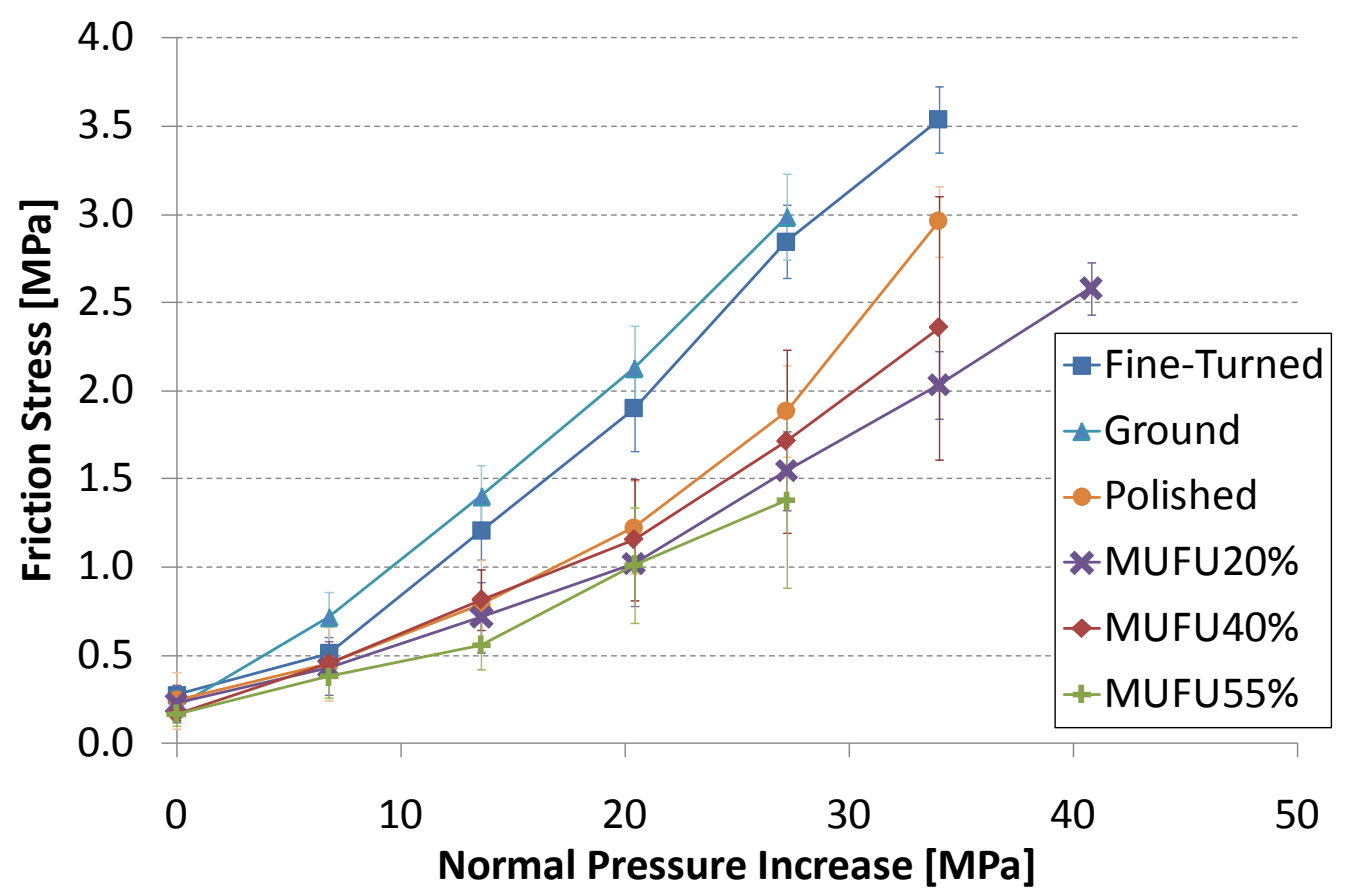

Fig.9. Resulting friction stresses of the tested surfaces vs. normal pressure increase.

The Coulomb friction coefficients $(\mu)$ are estimated by fitting a third order polynomial curve to each line and calculating the first order derivative at specific normal pressures. For each rod, five friction coefficients are calculated in the range 15-25 MPa. The results are shown in Fig. 10. The error bars indicate the variability of the friction coefficients and their calculation is explained in the following. Similarly to what done for the friction stresses, also for the friction coefficients the range was selected as a measure of deviation. The ranges are calculated by creating two plots similar to the one of Fig. 9: in the first one are plotted the maximum friction stresses; in the second one the minimum friction stresses. Afterwards the polynomial fitting is performed again in these two plots yielding the maximum and minimum friction coefficients and thus the ranges. These can be considered as rectangular distributions with limits plus and minus half range. According to [31], if a half range is divided by $\sqrt{3}$, the uncertainty contribution corresponding to a singular standard deviation is eventually found. The error bars shown in Fig. 10 represent indeed this contribution, which is the one to the form errors affecting the calculation of $\mu$. It is likely that this contribution is the most significant one in an uncertainty budget determined according to the guidelines given in [31]. 


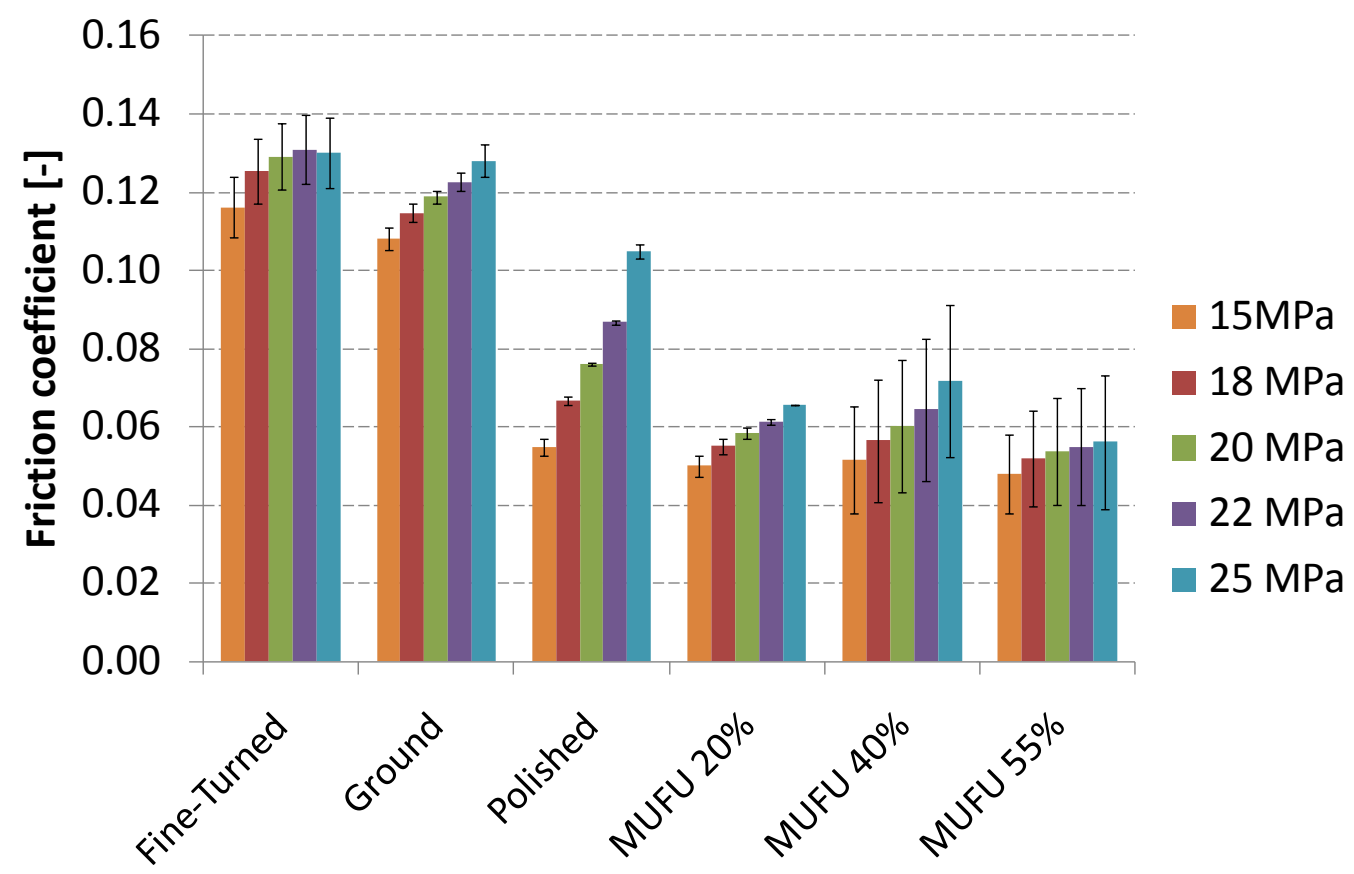

Fig.10. Friction coefficients comparison at different normal pressure increments.

Going back to the analysis of Fig. 10, it is confirmed that the fine-turned and the ground rod exhibit the highest friction coefficients, with $\mu$ average values comprised between 0.11 and 0.13 . On the other hand, the three multifunctional rods showed average friction coefficients of approximately 0.05-0.06, slightly increasing with the normal pressure. MUFU55\%, in spite of the high force variations within a stroke due to higher local normal pressure experienced, maintains a rather stable average friction coefficient at increasing pressures. The highest average friction coefficient $(\mu=0.072)$ detected on the multifunctional rods is reached by the MUFU40\% at a pressure increase of $25 \mathrm{MPa}$, which is well below the level of the fine-turned and ground ones despite the high variations. The polished rod showed low initial friction coefficients (comparable to the multifunctional rods ones), though steeply increasing till reaching $\mu=0.1$ at the highest pressure increment considered. The polished rod is therefore extremely sensitive to normal pressure changes, which is not favorable in practical applications.

The comparison demonstrates how the multifunctional surfaces leads to improved performances in terms of both friction forces and coefficients under pure sliding conditions compared to traditionally machined surfaces. The phenomenon can be explained by the particular conformation of the MUFU texture. The load is withstood by polished plateaus spaced out by large pockets for lubricant storage in which a hydrostatic pressure is built up. The effect of hydrostatic pressure build-up helps the surface to bear the load and is more important as the normal load increases. Generally speaking, smaller pockets, corresponding to lower equivalent film thicknesses, experience higher build-ups and are therefore particularly effective at high normal loads. As a matter of fact, the rod with lowest equivalent film thickness, MUFU55\%, displayed the lowest friction stresses and coefficients at high normal pressures. At low normal pressure this effect is not so important, so that the friction coefficients of the MUFU rods and even the polished rod are alike. At those pressures the nano-scale plateau roughness is of predominant importance: at similar roughnesses correspond similar behaviors. The comparison between the polished rod and the MUFU40\% one is enlightening in this matter. The two rods displayed similar roughnesses (the Ra values are respectively $0.047 \mu \mathrm{m}$ and $0.055 \mu \mathrm{m}$ and both have transversal polishing tracks) and superimposing friction forces trends and coefficients at low normal pressures. At higher pressures, instead, the absence of pressurized reservoirs in the polished rod caused an abrupt increase in contact and thus of friction forces and coefficients. The obtained results are in agreement on what found in previous research within the topic. Pettersson and Jacobson [13] tested several texture orientations in the sliding between a roller and piston in hydraulic motors, and displayed how parallel, transversal grooves reduce friction compared to the original tumbled surface. Moreover, their test shows similarities between the friction coefficient of the textured surface and a wellpolished one. Furthermore, a recently published article by Ramesh et al. [17] demonstrates how 
applying a dimpled texture on a pin for pin-on-disk testing can result in high degrees of friction reduction compared to the untextured case (up to $80 \%$ reduction).

The surface roughness was measured again after each test using the same strategy as before. The aim was to observe any possible difference with the original texture caused by wear occurred during the testing process. No wear was visible by simply visually inspecting the rods and the roughness measurements, listed in Table 2, confirmed the impression. The rod roughness results were indeed extremely close to the initial one and no plastic deformation of the asperities occurred. This was an expected result, because despite the high loads and the metal-to-metal contact, the rods underwent less than 100 sliding cycles each. The sleeve, instead, underwent all the cycles and was measured after each rod was tested. Looking at Table 3, the Ra value is almost unchanged with respect to the original one, but the Rt values are all higher with higher deviations. The Rt value, being the max peak-to-valley distance in the profile, is extremely sensitive to outliers, but, in this case, it can give information to occasional scratches accidentally probed by the stylus. By visually inspecting the sleeve, some scratches along the axial direction were detected. The higher Rt values together with higher deviations confirmed the hypothesis: some scratches were probed and influenced the results. In order to estimate the scratches depth, a replica of the sleeve inner surface was taken with a low viscosity casting silicone (Accutrans), which [32] demonstrated replicate faithfully every kind of surface. The replica was measured using a focus variation microscope (ALICONA Infinite Focus ${ }^{\circledR}$ ) [33] with a 20X magnification. In Fig. 11 the measurement is shown. The presence of a much rougher scratch is evident, highlighted by the transversal profile at the right-hand side of Fig. 11 (average of the profiles contained in the red area): the scratched zone has an arithmetic mean roughnesses $\mathrm{Ra}=0.271 \mu \mathrm{m}$, while the unworn zone has $\mathrm{Ra}=0.041 \mu \mathrm{m}$. Ploughing wear started therefore to occur on the mirror-polished surface of the sleeve after being tested at high loads and under mixed lubrication conditions.

Table 2. Characterization of AST rods after testing.

\begin{tabular}{|c|c|c|c|c|c|c|c|c|}
\hline \multirow[t]{2}{*}{$\begin{array}{l}\text { Specimen } \\
\text { Type } \\
\end{array}$} & \multicolumn{2}{|c|}{$\mathrm{Ra}[\mu \mathrm{m}]$} & \multicolumn{2}{|c|}{ Rt $[\mu \mathrm{m}]$} & \multicolumn{2}{|c|}{$\begin{array}{l}\text { Ra plateaus } \\
{[\mu \mathrm{m}]}\end{array}$} & \multicolumn{2}{|c|}{$\begin{array}{l}\text { Eq. Film } \\
\text { thickness }[\mu \mathrm{m}]\end{array}$} \\
\hline & Aver. & St. dev. & Aver. & St. dev. & Aver. & St. dev. & Aver. & St. dev. \\
\hline $\begin{array}{l}\text { Fine Turned } \\
\text { rod }\end{array}$ & 0.748 & 0.008 & 3.771 & 0.361 & & & & \\
\hline Ground rod & 0.507 & 0.037 & 4.464 & 0.570 & & & & \\
\hline Polished rod & 0.046 & 0.007 & 0.836 & 0.256 & & & & \\
\hline $\begin{array}{l}\text { MUFU 20\% } \\
\text { rod }\end{array}$ & & & 16.765 & 0.305 & 0.022 & 0.003 & 7.866 & 0.117 \\
\hline $\begin{array}{l}\text { MUFU 40\% } \\
\text { rod }\end{array}$ & & & 8.953 & 0.330 & 0.055 & 0.005 & 2.799 & 0.165 \\
\hline $\begin{array}{l}\text { MUFU 55\% } \\
\text { rod }\end{array}$ & & & 3.690 & 0.158 & 0.032 & 0.005 & 0.698 & 0.034 \\
\hline
\end{tabular}

Table 3. Characterization of the mirror-polished sleeve after each test.

\begin{tabular}{|l|l|l|l|l|l|l|l|l|l|l|l|l|}
\hline & \multicolumn{2}{|l|}{ Fine-Turned } & \multicolumn{2}{l|}{ Ground } & \multicolumn{2}{l|}{ Polished } & \multicolumn{2}{l|}{ MUFU20\% } & \multicolumn{2}{l|}{ MUFU40\% } & \multicolumn{2}{l|}{ MUFU55\% } \\
\hline & Aver. & St.d. & Aver. & St. d. & Aver. & Aver. & St. d. & St. d. & Aver. & St. d. & Aver. & St. d. \\
\hline Ra & 0.015 & 0.001 & 0.016 & 0.007 & 0.015 & 0.001 & 0.013 & 0.002 & 0.015 & 0.001 & 0.015 & 0.001 \\
\hline Rt & 0.239 & 0.078 & 0.193 & 0.095 & 0.184 & 0.030 & 0.215 & 0.083 & 0.223 & 0.105 & 0.210 & 0.090 \\
\hline
\end{tabular}



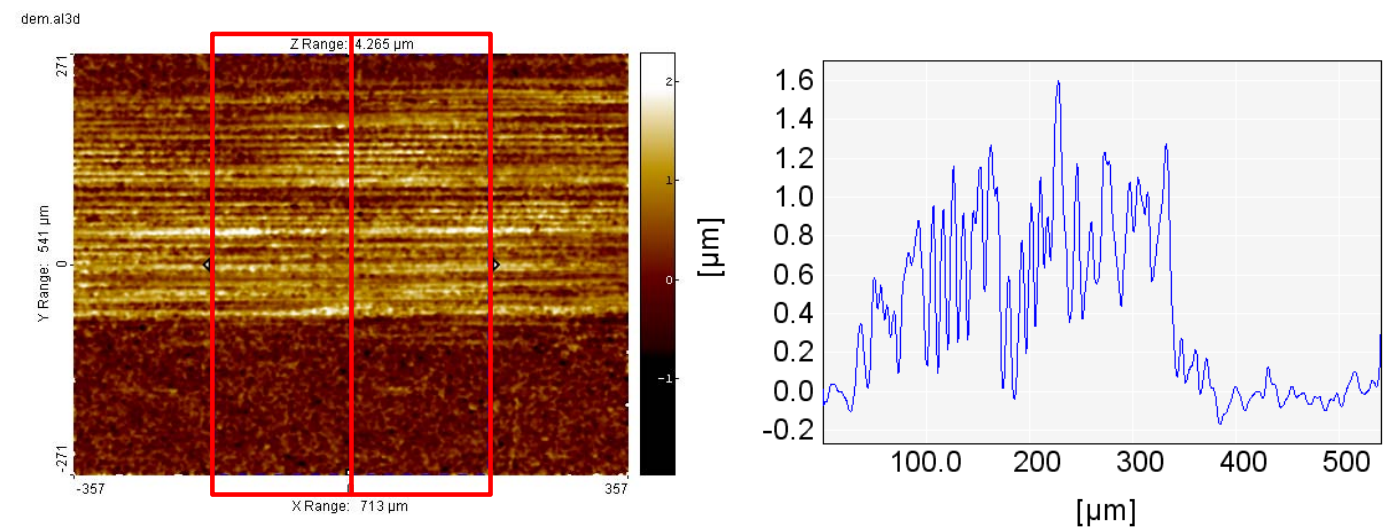

Fig.11. Optical measurement on replica of the inner surface of the sleeve and transversal average profile.

\section{Conclusions}

A newly developed Axial Sliding Test rig was utilized to screen the performances of regularly machined and multifunctional surfaces in terms of friction under pure sliding conditions. Six rods with different textures were tested under the same conditions, i.e. mirror-polished counterpart, lubrication, temperature, reciprocating movement settings, etc. Moreover, the tests were all carried out in the same range of normal pressure increments; therefore the recorded friction forces and the extrapolated friction coefficients could be compared. In particular the tests have shown:

- Multifunctional surfaces showed clearly lower friction forces and coefficients compared to ground or turned surfaces (up to 50\%);

- $\quad$ The polished surface displayed similar friction forces and coefficients with respect to the multifunctional rods at low normal pressure, but presented an abrupt force increment at high normal pressures due to the absence of lubricant reservoirs ;

- The presence of lubricant reservoirs is effective at high normal pressures due to the hydrostatic pressure increase of the trapped lubricant: in this particular case lower equivalent film thicknesses were related to higher pressure increases;

- $\quad$ No wear was detected on the rods, whereas the sleeve showed initial signs of ploughing wear due to repeated cycles under high pressure in a mixed-lubrication regime.;

- $\quad$ Systematic force trends were detected during the stroke and linked to form errors by means of force-geometry comparisons.

\section{Acknowledgments}

The authors would like to thank the Danish National Advanced Technology Foundation for funding this research under the project 'Manufacture and characterization of industrial multifunctional surfaces'.

\section{REFERENCES}

[1] Bruzzone, A.A.G., Costa, H.L., Lonardo, P.M., Lucca, D.A.: Advances in engineered surfaces for functional performance. CIRP Ann Manuf Technol 57, 750-769 (2008).

[2] De Chiffre, L., Kunzmann, H., Peggs, G.N., Lucca, D.A.: Surfaces in Precision Engineering, Microengineering and Nanotechnology. CIRP Ann Manuf Technol 52(2), 561-577 (2007).

[3] Evans, C.J., Bryan, J.B.: “Structured”, “Textured” or “Engineered” Surfaces. CIRP Ann Manuf Technol 48(2), 541-556 (1999).

[4] Stachowiak, G., Podsialdo, P.: 3-D Characterization, Optimization and Classification of Textured Surfaces. Tribol Lett 32, 13-21 (2008). 
[5] Santochi, M., Vignale M.: A study on the functional properties of a honed surface. CIRP Ann Manuf Technol 31(1), 431-434 (1982).

[6] Stout, K.J., Spedding, T.A.: The characterization of internal combustion engine bores. Wear 83, 311-326 (1982).

[7] Whitehouse, D.J.: Some theoretical aspects of a practical measurement problem in plateau honing. Int J Prod Res 21(2), 215-221 (1983).

[8] Stout, K.J., Sullivan, P.J., Dong, W.P., Mainsah, E., Luo, N., Mathia, T., Zahouani, H.: The development of methods for the characterization of roughness in three dimensions. Commission of the European Communities, UK (1993).

[9] Holmberg, K.: The mechanism of Lubrication in Low Speed Rolling Contacts. J Tribol 111, 703-707 (1989).

[10] Sørensen, C.G., Bech, J.I., Andreasen, J.L., Bay, N., Engel, U., Neudecker, T.: A Basic Study of the Influence of Surface Topography on Mechanisms of Liquid Lubrication in Metal Forming. CIRP Ann Manuf Technol 48(1), 203-208 (1999).

[11] Koszela, W., Pawlus, P., Galda, L.: The effect of oil pockets size and distribution on wear in lubricated sliding. Wear 263, 1585-1592 (2007).

[12] Reng, N., Nanbu, T., Yasuda, Y., Zhu, D., Wang, Q.: Micro Textures in ConcentratedConformal-Contact Lubrication: Effect of Distribution Patterns. Tribol Lett 28, 275-285 (2007).

[13] Pettersson, U., Jacobson, S.: Textured surfaces for improved lubrication at high pressure and low sliding speed of roller/piston in hydraulic motors. Tribol Int 40, 355-359 (2007).

[14] Costa, H.L., Hutchings, I.M.: Effects of die surface patterning on lubrication in strip drawing. J Mater Process Technol 209, 1175-1180 (2009).

[15] Vrbka, M., Šamánek, O., Šperka, P., Návrat, T., Křupka, I., Hartl, M.: Effect of surface texturing on rolling contact fatigue within mixed lubricated non-conformal rolling/sliding contacts. Tribol Int 43, 1457-1465 (2010).

[16] Kaminski, J., Facht, J., Sjoblom, U.: Manufacturing of Dimpled Surfaces in Hard Turning and subsequent Honing operation. Proc $12^{\text {th }}$ euspen Int Conf, Stockholm, Sweden, 49-52 (2012).

[17] Ramesh, A., Akram, W., Mishra, P.S., Cannon, A.H., Polycarpou, A.A., King, W.P.: Friction characteristics of microtextured surfaces under mixed and hydrodynamic lubrication. Tribol Int 57, 170-176 (2013).

[18] Friis, K.S., Godi, A., De Chiffre, L.: Characterization and robust filtering of multifunctional surfaces using ISO standards. Meas Sci Technol 22, art.125101 (2011).

[19] Eriksen, R.S., Arentoft, M., Grønbæk, J., Bay, N.: Manufacture of functional surfaces through combined application of tool manufacturing process and Robot Assisted Polishing. CIRP Ann Manuf Technol 61(1), 563-566 (2012).

[20] Godi, A., Grønbæk, J., Mohaghegh, K., Klit, P., De Chiffre, L.: An Axial Sliding Test for machine elements surfaces. Proc $15^{\text {th }}$ NordTrib, Trondheim, Norway, ISBN 978-82-14-05270-1 (2012).

[21] Grønbæk, J.: Stripwinding of tool for bulk metal forming. Ph.D. Thesis, Technical University of Denmark (1981). (In Danish).

[22] Grønbæk, J.: Application of stripwinding tool to large reduction cold forging processes. Proceedings of the North American Manufacturing Research Conference (NAMRC-X), Hamilton, Canada, 225-232 (1982). 
Tribol Lett (2013) 51(1):171-180

DOI 10.1007/s11249-013-0162-6

[23] Grønbæk, J.: Stripwound cold-forging tools - A technical and economical alternative. J Mater Process Techn 35, 483-493 (1992).

[24] Sidenius, I.: Aksler. Kiler, fedre og splines. Krympning og roterende skiver. Kompendium til maskinelementer KP4, Polyteknisk Forlag, Denmark (1971). (In Danish).

[25] Texaco Multifak ${ }^{\circledR}$ EP 0,1,2. http://www.rolandjrobertdistributor.com/files/Multifak_ep.pdf. Accessed $29^{\text {th }}$ November 2012.

[26] Blunt, L., Jiang, X.: Advanced techniques for assessment surface topography. Kogan Page Science, UK (2003).

[27] Brinkmann, S., Bodschwinna, H., Lemke, H.W.: Accessing roughness in three-dimensions using Gaussian regression filtering. Int J Mach Tools Manuf 41, 2153-2161 (2001).

[28] Godi, A., Khüle, A., De Chiffre, L.: A plateau-valley separation method for multifunctional surfaces characterization. Proc $12^{\text {th }}$ euspen Int Conf, Stockholm, Sweden, 190-193 (2012).

[29] Guo, K., Zhang, X., Li, H., Meng, G.: Non-reversible friction modeling and identification. Arch Appl Mech 78, 795-809 (2008).

[30] Wojewoda, J., Stefański, A., Wiercigroch, M., Kapitaniak, T.: Hysteretic effects of dry friction: modeling and experimental studies. Phil Trans R Soc A 366, 747-765 (2008).

[31] JCGM 100: Evaluation of measurement data - Guide to the expression of uncertainty in measurement (2008).

[32] Gasparin, S.: Verification of tolerance chains in micro manufacturing. Ph.D. Thesis, Technical University of Denmark (2012).

[33] Alicona Imaging GmbH: Alicona Infinite Focus ${ }^{\circledR}$, IFM Manual (2009). 